\title{
Editorial
}

\section{Juventude e política em sociedades em mudança}

\section{Víctor Muñoz Tamayo ${ }^{1}$, Camila Ponce Lara ${ }^{2}$}

Refletir e produzir conhecimento sobre o vínculo atual entre juventude e política requer assumir, de antemão, que se trata de conceitos cujas dimensões se encontram em constante definição, as que no se separam das próprias apostas de construção social que estabelecem os posicionamentos de cada analista.

Por uma parte, a política, como âmbito conflitivo da construção de sociedade, inclui o debate relativo a entendê-la e defini-la, com seus limites, vínculos, formas e possibilidades. Como sugere Norbert Lechner (2006), o cientista social pode usar um conceito de política, ligá-lo a uma determinada concepção do social e se posicionar em torno de definições, mas elas não alcançam a universalidade nem a objetividade, pois se acham conectadas com modos e sentidos de ação em tensão e disputa. Em resumo, pensar e problematizar a política faz parte do fazer político, o

Historiador. Doutor em Estudos Latino-americanos pela UNAM, México. Investigador do Centro de Investigações e Ciências Sociais e Juventude, Universidade Católica Silva Henríquez, Chile. Contato: vmunozt@ucsh.cl

2 Socióloga. Doutora em Sociologia, École des Hautes Études en Sciences Sociales (EHESS), Paris, França. Pesquisadora do Centro de Investigações e Ciências Sociais e Juventude, Universidade Católica Silva Henríquez, Chile. Contato: cponce@ucsh. $\mathrm{cl}$ 
que o torna necessariamente conflitivo e esquivo ao consenso de absolutos.

Por outra parte, a juventude é sempre, como o manifestou Bourdieu (1990), uma palavra estruturada socialmente e ao mesmo tempo estruturante da sociedade, que estabelece âmbitos, características, distinções e limites a quem inclui. Palavra que abrange a pluralidade de modos e condições desde as quais as novas gerações se incorporam às ordens e intervêm na sua produção e transformação. E, como assinalaram Margulis e Urresti (1996), trata-se de um conceito complexo e plural, no que dimensões fáticas referidas ao biológico e o vital se relacionam em uma mutua determinação com o socio-histórico, o que faz das idades construções culturais, não naturais nem essenciais.

O século XX latino-americano apresentou-nos múltiplas emergências de movimentos sociais e militâncias ancoradas em identidades juvenis que interpretaram a realidade social e intervieram nela em termos políticos. Desde o grito antioligárquico da fundação da Federação de Estudantes do Chile FECH (1906), e o reformismo estudantil de Córdoba (1918), até os movimentos estudantis dos anos 60, tingidos de sangue en Tlatelolco, a ação juvenil foi em grande medida ação estudantil. Nos anos oitenta, as crises econômicas e políticas levaram os olhares dos analistas aos territórios, onde organizações da juventude dos bairros marginalizados demostraram que a condição estudantil não era a única realidade a ser politizada desde identidades que enfatizavam nas vivências, formas e práticas juvenis. Para os anos 90, os diagnósticos de fragmentação pós-moderna e crise dos grandes relatos; a particular visibilidade que adquiriam as culturas e estilos juvenis no quadro da globalização e as novas tecnologias informáticas; a crise ideológica e política das esquerdas; o predomínio de um estado neoliberal subsidiário quanto ao mercado e seus consequentes processos de tecnificação administrativa da política, levaram as ciências sociais a deixar de observar, com a centralidade de antanho, a atores clássicos do século XX, como eram os trabalhadores e os estudantes. Isto até que, a partir de di- 
versos eventos —desde a longa greve da UNAM do México, em 1999, até a primavera estudantil de 2011 no Chile-, os atores juvenis e estudantis, com suas particulares condições ancoradas no neoliberalismo, mexeram com as realidades complexas de nossos países, produzindo novos olhares, práticas e sentidos relativos a vincular política e juventude.

Embora no passado recente tenham abundado as análises que tendiam a ver na relação juventude e política uma metáfora exagerada de diagnosticadas condições de desafeição social ante os temas públicos, tais análises têm sido devidamente revisadas perante reiterados ciclos de movimentos sociais juvenis em conflito com os Estados ou os grandes poderes econômicos. A aquilo se soma que certas emergências militantes, com peso significativo de jovens gerações, têm alterado os tradicionais esquemas de conformação e confrontação em diversos sistemas de partidos. Em síntese, recentes conjunturas dizem-nos que a política, em relação com os jovens, ultrapassa as noções de "apatia", "desafeição" ou "politicidade" como pura expressividade de descontentamento por parte de determinadas culturas ou estilos juvenis, e que estão as condições para analisar participação, ativismos e militância juvenil política, o que supõe abordar modos e discursos de politização e de relação entre atores juvenis, Estados e sistemas políticos.

Por isso, o convite do presente seção do dossiê é para revisarmos as formas em que se estão produzindo relações entre juventude e política, tarefa com a que, aliás, se problematizam tais categorias em relação com o social. É também um chamado a unirmos as perspectivas dos estudos dos movimentos sociais, o protesto e os ativismos, com o estudo das militâncias, os partidos e a organização da política nas sociedades.

Acreditamos que uma distinção útil para entendermos o carácter deste tipo de problemáticas contemporâneas, é aquela que, quanto exercício analítico, assume uma diferenciação entre "a política", entendida como campo instituído formalmente, com proce- 
dimentos, papéis a serem desempenhados, temas e lógicas específicas (partidos, sistema de partidos, participação eleitoral), e uma dimensão "do político" que corresponderia ao modo cotidiano em que os sujeitos assumem a construção de realidade social e pública. Desde esse olhar, o fato de que "a política" seja continuamente redefinida por temas, conflitualidades e dimensões que emanem "do político", seria a condição para que não se separe do sociocultural transformando-se em um espaço de elite (Garretón 1994, 2004 , 2007). Aliás, o modo em que, desde a sociedade, começam a propor-se temas e problemas para serem tratados coletivamente quanto decisões públicas, quer dizer, o modo em que determinados temas passam ao terreno do político, constituiria o que conhecemos como processos de politização do social (PNUD, 2015).

A distinção entre o político e a política é útil para a análise, desde que entendamos que não há uma separação absoluta, rígida e estática entre as dinâmicas associadas à ação coletiva dos movimentos sociais, e o âmbito em que as militâncias, mais ou menos instituídas, disputam a condução do Estado. Entre outras coisas porque as militâncias, quer sejam formalizadas ou não, emergem desde dinâmicas arraigadas em sujeitos sociais inseridos no político. Basta ver todas as experiências latino-americanas em que ativismos setoriais inseridos em movimentos sociais têm se confundido, imbricado, ou têm evoluído para militâncias políticas com relativa inserção nos sistemas de partidos. O anterior tem mudado o campo do político, mas também o da política, de modo que os cientistas sociais devemos prestar particular atenção ao terreno da interrelação de tais dimensões.

Em sintonia com o anterior, podemos indicar que os trabalhos da presente seção do dossiê circulam em dois grandes âmbitos conectados. Por uma parte, o que se vincula com a ação coletiva contenciosa de atores juvenis em processos de politização e, por outro, o de atores juvenis politizados que, constituídos em militâncias políticas orgânicas, tradicionais ou emergentes, atuam desde o espetro das esquerdas ou as direitas com mais ou menos presença no sistema político institucionalizado. A seguir, e 
em consideração aos processos recentes de politização juvenil na América Latina, daremos uma revisão a problemas e temas relevantes presentes em cada uma destas duas dimensões. Logo daquilo, serão apresentados os artigos do dossiê, relevando o modo em que estes abordam os debates assinalados.

\section{Mobilizando desde o político. Protesto, politização e Estado desde a ação coletiva juvenil}

Durante 2011 gera-se, em nível global, uma série de ciclos de protestos que se conhecem como "movimentos de praças" ou "novíssimos movimentos sociais". Os primeiros protestos originaram-se na Tunísia, contra o governo autoritário de Ben Ali, e logo se somaram países como o Egito, a Líbia, a Síria ou o Iêmen. De maneira quase paralela originaram-se as mobilizações em países ocidentais contra a crise econômica, política e social. Estes novíssimos movimentos sociais (Juris et al., 2012) foram descritos como diferentes dos "novos movimentos sociais" que na altura trataram sociólogos como Alain Touraine (2006), aqueles que foram se conformando em torno de identidades que iam para além do conflito capital-trabalho e do clássico movimento operário, e que tiveram causas tão diversas quanto as dos movimentos ecologistas, feministas e estudantis. De acordo com alguns analistas, embora os novíssimos movimentos sociais partilhassem a amplidão cultural dos "novos movimentos", tinham como uma de suas principais características distintivas um papel preponderante das novas tecnologias e as plataformas online. Por outra parte, tratava-se de ativismos que também tinham diferenças com as militâncias clássicas adscritas ou relacionadas com instituições formais (Pudal, 2011). Para alguns analistas, havia nestas experiências uma presença notável de "outro ativismo" (Pleyers, 2010), o chamado "alter-ativismo", que se caracteriza por compartilhar valores com eixo no indivíduo, suas opções e estilo de vida, as ações criativas, a utilização da internet e a necessidade de mudar o mundo a partir das próprias práticas cotidianas. 
Um dos casos de mobilizações "novíssimas" mais significativas em ocidente foram as desenvolvidas na Espanha com os denominados "Indignados do 15-M". Neste movimento foram realizados acampamentos na Porta do Sol, que eram constantemente desalojados e instalados novamente. $\mathrm{O}$ adjetivo dos "indignados" nestas mobilizações espanholas nasce a partir do livro Indignai-vos! de Stéphane Hessel (2011), texto que, aliás, visa refletir sobre a necessidade de gerar uma mudança de mentalidade, contra a indiferença e a favor de um descontentamento ativo. Também emergem mobilizações de praças em Nova York, na praça de Occupy Wall Street; em Istambul, na praça de Gezi, ou em Syntagma em Atenas, com características semelhantes. A particularidade destas mobilizações, destacada por autores como Castells (2012), é que todas elas são horizontais; não há organizações políticas liderando os protestos, nem se observam líderes permanentes e incontestáveis que as encabecem.

No caso latino-americano, podemos observar que há muitos elementos que se assemelham àquelas mobilizações de praças, mas também encontramos outras particularidades que os distinguem. Por exemplo, este ciclo latino-americano tem a particularidade de ser eminentemente estudantil, como são aquelas mobilizações estudantis chilenas de 2011, a MANE na Colômbia ou o \#EuSou132 no México. Nestes casos, vemos que os movimentos se diferenciam por contarem com líderes carismáticos e estruturas organizativas próprias das universidades, particularmente no Chile e na Colômbia, mas se assimilam no tipo de ativismo e o papel importante da internet na sua organização, que é central, por exemplo, no caso mexicano. Deste modo, realizam-se pesquisas com foco na internet e particularmente nas plataformas online como Facebook e Twitter. Por exemplo, publicações que realizam análises comparadas entre diferentes casos perante os usos da internet e a geração de redes (Galindo, 2016), ou análises específicas de Twitter que revelam sua institucionalização como meio de comunicação (García et al., 2014), para nomear alguns. 
Para além da análise de quadros para a ação coletiva, entre os que destacam em grande medida os repertórios (Aguilera, 2012; Fernández, 2013), a criatividade dos protestos é uma linha importante para assinalar as novas formas de ação coletiva que se tornam fortemente visíveis no espaço público. Por uma parte, os acampamentos desenvolvidos por uma geração juvenil são instâncias que permitem criar espaços de experiência (Pleyers, 2016) e gerar vivências comuns entre os diferentes manifestantes; mas também os flash mobs —ou multidões instantâneas-, como os bailes, beijos em massa ou corridas pela educação, que conectavam a estranhos em prol de um fim comum (Ponce e Miranda, 2016), como era a educação gratuita, de qualidade e sem lucro, como exigiam os estudantes no Chile; ou para proteger o ensino superior público e gratuito, no caso colombiano.

Por último, em 2018 observamos um novo momento de mobilizações juvenis, desta vez com um carácter feminista. Estas mobilizações se enquadram principalmente em países ibero-americanos, onde destacam as revoltas dos lenços verdes argentinos, pelo aborto livre, seguro e gratuito; o movimento estudantil feminista chileno, que tem lugar principalmente em instituições de educação superior e que exige educação não sexista e o fim do assédio sexual; as revoltas contra a condena da "Manada" na Espanha, e o movimento \#EleNão contra Bolsonaro no Brasil (Larrondo e Ponce, 2019).

Em síntese, o social tem se politizado, e ali têm estado identidades constituídas desde a diversidade de mundos juvenis, na qual a classe, o território, a condição estudantil, as culturas juvenis, o gênero, a sexualidade, a etnia, intervêm como dimensões desde as quais se articula a politicidade juvenil. Nesse sentido, vemos que nenhuma dimensão do juvenil é restritiva em relação a essa diversidade de lugares de identidade, como o podemos ver no protagonismo do ator estudantil, que continua se mostrando como expressão de agravos e demandas que apelam ao conjunto de desigualdades reproduzidas ao interior dos sistemas 
educativos, e expressadas na relação dos e das estudantes com o Estado, o mercado e a sociedade em seu conjunto.

\section{Rumo à política. Gerações, militâncias juvenis e sistema político na contemporaneidade}

Por muito tempo lemos, nos estudos de juventude, o diagnóstico do declínio da participação política militante. A desafeição social com a política institucional, expressada no decaimento da participação eleitoral, assim como o declínio dos partidos de massas, tiveram nas novas gerações um exemplo reiterado, como metáfora de um devir no que o político se afastava da política. Em tal contexto, houve uma tendência nas análises sociais em destacar o político e a politicidade dos protestos e os movimentos juvenis, mas não assim as orgânicas especificamente político-militantes, mais ou menos inseridas nos sistemas de partidos. No entanto, há alguns anos, têm sido os mesmos processos do continente os que têm levado aos cientistas sociais a observarem trânsitos de politização juvenil que têm trazido com eles ciclos de repartidarização, os que, por sua vez, têm intervindo nos campos políticos nacionais.

A Argentina e o Chile têm sido dois dos países em que determinados contextos têm motivado que, desde o estudo da politização juvenil e os movimentos sociais, sejam analisadas também as militâncias emergentes expressadas em tais movimentos (Vommaro, 2015; Vásquez, Vommaro, Núñez e Blanco, 2017; Muñoz e Durán, 2019). Ali têm chegado a ser de particular interesse processos como a emergência juvenil de esquerdas, direitas e centros, que por uma parte recolhem tradições políticas e as ressignificam, e, por outra, inovam nos modos, sentidos e lógicas da ação política. Para a América Latina, tem sido particularmente interessante também a observação do processo espanhol, no que a crise de representação dos partidos tradicionais, no marco do desastre econômico, abriu espaços a novas militâncias que reconheciam como ancoragem indentitária lei- 
turas, indignações ou desafeições expressadas por movimentos sociais com presença juvenil, como se aprecia no caso da relação entre Podemos e o 15-M.

A emergência de tipos de militâncias que aspiram ao poder expressado institucionalmente, mas também a ser ator do poder construído desde os movimentos sociais, não são uma novidade à luz do longo século XX. No entanto, sim são no marco de um neoliberalismo que tinha atingido algum sucesso na tarefa de tecnificar a política e despolitizar o social, quanto condição básica dos consensos relativos à aceitação do modelo económico. O ano 2011 no Chile foi, naquele sentido, a expressão clara de um movimento juvenil estudantil que não só assumiu-se ele próprio como político, mas também acusou à política instituída de não cumprir sua tarefa de representar politicamente os diversos interesses expressados na sociedade civil. Denunciando um vazio de conflitividade no sistema de partidos, o movimento falou de uma democracia deficitária, capturada em consensos estagnados da elite, que se instalava como âmbito de administração do já dado, mas não quanto canal para as demandas transformadoras emanadas desde a sociedade. Nessa linha, não foi estranho que grande parte das militâncias estudantis convergisse logo em processos nacionais de emergência de novos partidos políticos, que falaram de mudar a política desde as próprias instituições, tarefa para a qual, segundo os seus próprios conceitos, deviam ganhar representação parlamentar, apostar em dirigir governos locais, elaborar apostas em relação a disputarem o governo nacional, mas sem perderem a conexão com o poder dos movimentos sociais.

Ao calor deste tipo de transformações, os estudos de juventude, política e militância constituem âmbitos prioritários desde os que se pode analisar a conflitiva construção do público a partir do foco socioetário e sociogeracional. Desde ali podem se elaborar olhares que partem da atenção no juvenil, mas se dirigem a fenômenos que o transcendem, e que se relacionam com as transformações contemporâneas nas conexões entre Estado, economia 
e sociedade. A política está mudando, sempre o tem feito, e observarmos as novas gerações continua sendo fundamental para entendermos o processamento e articulação dessas mudanças.

\section{Os artigos da seção do dossiê}

Iniciamos a seção do dossiê com o artigo intitulado "Movimentos juvenis no Brasil e no México, coordenadas para uma análise de subjetivação e desmobilização social", de Héctor Andrade. Este texto analisa a subjetivação e desmobilização social dos jovens ativistas dos movimentos \#EuSou132, Passe Livre, \#TodosSomosPolitécnico e Ayotzinapa, destacando a relação entre a subjetivação, os meios de comunicação e o vínculo com o Estado. A partir de uma metodologia qualitativa com base em entrevistas, o autor propõe uma leitura sobre a desmobilização social gerada desde o Estado, a partir de diferentes dispositivos, como a repressão, a vigilância e a violência.

Segue o texto denominado "Continuidades e rupturas dos protestos universitários no Chile da pós-ditadura (1990-2014)", desenvolvido por Cristóbal Villalobos e Camila Ortiz. Esta pesquisa, de carácter descritivo e quantitativo, busca estudar, através da análise de eventos de protestos, os ciclos e tendências nas mobilizações estudantis do Chile pós-ditadura entre 1990 e 2014. Os pesquisadores, a partir de sua análise, perseguem desmontar algumas das teses apresentadas por diferentes pesquisadores que centram seu trabalho no movimento estudantil, tais como: a desmobilização durante os noventa e o aumento de conflitividade durante os 2000, a mudança de tácticas e demandas do movimento estudantil, e que a intensidade do conflito tem aumentado durante as últimas décadas.

As autoras Mariana Lerchundi e María del Rocío Alonso apresentam o artigo "Violência institucional e participação política juvenil: a experiência da Marcha do Boné (Córdoba)", baseado em uma pesquisa sobre a estigmatização e a falta de reconhecimento de jovens das cidades Río Cuarto e Córdoba na Argentina, 
no marco das mobilizações da Marcha do Boné. Esta pesquisa qualitativa, sobre a base de entrevistas em profundidade e etnografias virtuais, busca compreender as significações e subjetividades destes jovens fortemente estigmatizados.

Por sua parte, o pesquisador Juan Fernández contribui com "Politização estudantil e o papel da ocupação nas mobilizações de 2011 no Chile". A partir de uma metodologia de caráter qualitativo, com base em grupos de discussão com ativistas de diferentes universidades e liceus, o autor busca analisar a relação entre as ocupações e a politização daqueles ativistas não dirigentes do movimento estudantil de 2011. Uma das principais descobertas deste artigo é a apropriação e ressignificação da política pelos sujeitos jovens, além do papel preponderante da ocupação como espaço de autonomia e aprendizagem política.

Já no que diz respeito às militâncias juvenis e sua conexão com a política institucional, está o texto de Marion Di Méo intitulado: "Da rua ao parlamento: trajetórias e repertórios de uma geração de estudantes. Chile, 2006-2017". A autora analisa conexões entre as mobilizações de 2006 e 2011, oferecendo a tese de uma continuidade geracional a partir das vivências e percepções de seus atores, primeiro como estudantes secundários e logo como universitários. Aprofunda-se nos repertórios da ação coletiva e sua adaptabilidade estratégica, detendo-se no trânsito de algumas lideranças rumo à política institucional.

Um olhar que atende também o foco geracional, mas dentro de um marco histórico de revisão das trajetórias de militâncias juvenis de esquerda durante ditadura, é o que apresenta o artigo de Carmen Gemita Oyarzo "Nossas lutas de ontem: vozes militantes e narrativas geracionais sobre a derrota e os desafios atuais da esquerda chilena (1990-2018)". A partir da abordagem do conceito de "geração" em sua dimensão de construção indentitária, quer dizer, quanto identidade geracional, Oyarzo faz uma rigorosa análise qualitativa das narrativas de ex-militantes de esquerda, atendendo 
ao modo em que tais militantes configuram noções comuns de sentido, em relação à história compartilhada e às leituras do presente.

Também focado na análise da esquerda chilena, o penúltimo texto o dossiê da seção escreve-o Aaron Briceño e se intitula "O movimento universitário de Valparaíso e o surgimento de uma nova esquerda no Chile". Este artigo faz uma análise do movimento estudantil universitário de Valparaíso entre 2006 e 2016, centrando-se na esquerda estudantil e como ela se insere em processos de articulação de uma nova esquerda no Chile e com presença nas estruturas formais de representação democrática.

Finaliza esta seção o texto de Rodrigo Torres e Juan Carlos Sánchez intitulado "Educação, mobilizações de estudantes e conflito político no Chile e na Colômbia: algumas reflexões desde uma perspectiva comparada". A partir da análise de contenda política, com foco na estrutura de oportunidades políticas desenvolvida em cada caso estudado, os autores comparam as mobilizações estudantis recentes do Chile e da Colômbia, apresentando as semelhanças nos processos políticos, assim como a evolução dos repertórios de ação destes jovens mobilizados.

\section{Referências}

Aguilera, O. (2012). Repertorios y ciclos de movilización juvenil en Chile (2000-2012). Utopía y praxis latinoamericana: revista internacional de filosofía iberoamericana y teoría social, 101-108.

Bourdieu, P. (1990). La juventud no es más que una palabra. En Sociología y Cultura. México D.F.: Grijalbo/CNCA.

Castells, M. (2012). Networks of Outrage and Hope. Cambridge: Polity Press.

Fernández, J. (2013). Movimiento estudiantil en Chile (2011): repertorios de acción, marcos de acción colectiva, impactos y desafíos para la política pública. Circunstancia, Revista de Ciencias Sociales del IUIOG, 11(31).

García, C. et al. (2014). What can Twitter tell us about social movements' network topology and centrality? Analysing the case of the 2011-2013 Chilean student movement. International Journal 
of Organisational Design and Engineering, 4(3-4), 317-337.

Garretón, M. A. (1994). La faz sumergida del iceberg. Estudios sobre la transformación cultural. Santiago de Chile: LOM-CESOC.

Garretón, M. A. (2007). Del postpinochetismo a la sociedad democrática. Santiago de Chile: Debate.

Garretón M. A. et al. (2004). América Latina en el siglo XXI. Hacia una nueva matriz sociopolítica. Santiago de Chile: LOM.

Galindo, L. (2016). La red como cronotopo: Internet y prácticas políticas en el Movimiento Estudiantil Colombiano Mane y Occupy São Paulo. Observatorio (OBS*), 10(Especial), 141-160.

Hessel, S. (2011). jIndignaos! Barcelona: Destino.

Juris, J., Pereira, I. e Feixa, C. (2012). La globalización alternativa y los novísimos movimientos sociales. Revista del Centro de Investigación, Universidad La Salle, 10(37), 23-39.

Larrondo, M. e Ponce, C. (2019). Activismos feministas jóvenes en América Latina. Dimensiones y perspectivas conceptuales. En Activismos feministas jóvenes: Emergencias, actrices y luchas en América Latina. Buenos Aires: CLACSO (Em edição).

Lechner, N. (2006). La conflictiva y nunca acabada construcción del orden deseado. En N. Lechner, Obras escogidas, tomo 1. Santiago de Chile: LOM.

Margulis, M. e Urresti, M. (1996). La juventud es más que una palabra. En M. Margulis, La juventud es más que una palabra. Ensayos sobre cultura y juventud (pp. 13-30). Buenos Aires: Editorial Biblos.

Muñoz, V. e Durán, C. (2019). Los jóvenes, la política y los movimientos estudiantiles en el Chile reciente. Ciclos sociopolíticos entre 1967 y 2017. Revista Izquierdas, 45, USACH IDEA.

Pleyers, G. (2010). Alter-globalization. Becoming actors in the global age. Cambridge: Polity Press.

PNUD. (2015). Desarrollo humano en Chile. Los tiempos de la politización. Santiago de Chile: Programa de Naciones Unidas Para el Desarrollo.

Ponce, C. y Miranda, N. (2016). Redes de confianza online y flash mobs: movilizados por la educación. Observatorio $\left(O B S^{*}\right)$, 10, 161-175.

Pudal, B. (2011). Los enfoques teóricos y metodológicos de la militancia. Revista de Sociología, (25), 17-35. 
Touraine, A. (2006). Los movimientos sociales. Revista Colombiana de Sociología, 27, 255-278.

Vázquez, M., Vommaro, P., Núñez, P. e Blanco, R. (2017). Militancias juveniles en la Argentina democrática. Trayectorias, espacios y figuras de activismo. Buenos Aires: Imago Mundi.

Vommaro, P. (2015). Juventudes y políticas en la Argentina y en América Latina. Buenos Aires: CLACSO. 